\title{
Discrete Event Simulation Software for Agent-Based Supply Chain Demand
}

\author{
Haider Al-Fedhly ${ }^{1, *}$ and Duncan Folley ${ }^{2}$ \\ 1 Intelligent Manufacturing Systems Centre (IMSC), University of Windsor 1212 Centre for Engineering \\ Innovation (CEI 1212) 401 Sunset Ave., Windsor, Ontario, N9B 3P4, Canada \\ 2 School of Built Environment, Engineering \& Computing Leeds Beckett University, Leeds LS6 3QT, United \\ Kingdom \\ *Corresponding author: fedhly@gmail.com
}

\begin{abstract}
Customer satisfaction is the ultimate goal of the supply chain. At the same time, business success relies on the income made from offering service. With increasing competition, complexity, higher variety and advancing technology; supply chain management SCM is becoming challenging. Many tools have been commercialised to assist in the analysis, design, management, and evaluation of supply chains (SC). Simulation software is one of common manager's aids that facilitates the modelling and calculation of more complicated situations.

Firstly, demand have been defined based on the literature to develop an appropriate concept. Complex elements of external and internal variables affect the SC performance especially at service level. The purpose of this research is to analyse different aspects of demand then to develop a demand agent that is able to simulate a wide range of real life demand cases within the context of supply. It has been utilized as a development and modelling environment for several reasons. In addition to its 3D GUI, it offers powerful development and customizations by its features. Moreover, it can be a promising tool if combined with the numerical based applications in order to transform supply chain performance to a next level by adopting the white-box examining method and value streaming.

Agent based demand have been developed using the provided $\mathrm{C}++$ programming facilities of the chosen simulation software application. Virtually, demand object can be used as a powerful option in SC or production network simulation as well. In addition, it can be used in both pull and push production strategies instead of just a "sink" within the environment. An experiment has been carried out to examine the effect of different distribution patterns. Four pattern have been tested for both supply and demand: uniform, normal, triangular, and exponential. A supply object is used to represent the product end line. It has been observed that proposed demand object behaved according to the design input. Result shows that distribution type at the same frequency have different effect on service level. It also suggests that waiting variable can significantly affect the service level.
\end{abstract}

Key words: Agent Based Demand, Supply Chain Simulation, Demand for Digital Shadow Technology.

\section{1- Overview}

\section{A. Background}

Basic product design is usually derived from customer needs as usually referred by designer functional requirements. This principal is very close to the fact when every customer 
requirement is mapped into product domain. However, production lines are not designed to satisfy individual needs but it tries to approach large number of common desired functions as known as an economy of scale or even economy of scope. Manufacturing in large quantity can reduce the cost of the product and have better economic performance. The trade off such practice is to try to satisfy multiple variable factors, including economic optimization, which might compromise customer value. Dealing with such complex, multi variable, optimization is becoming a major challenge for the supply chain managers, as the scope of this research, in order to achieve a better supply chain performance. Generally, satisfaction varies from customer necessity fulfilment to adding value services as well as product utilization. The rapid developing technology and information sharing networks made product's customization as well as customer expectation from necessity and keep trying to reach mature enough value adding product point of view. However, the study focuses on demand in terms of associated uncertainties on service level.

\section{B. Quantitative literature research}

Production optimization, as a demand management, is ongoing challenge in today's production/ distribution environment. Lots of research has dealt with demand trying to optimize products to be available only at demand time. Different methods have been investigated under different term: Demand Chain Management, Demand Driven Production, and Demand Forecasting, demand management, and demand optimization.

These keywords have been used in Scopus search engine to find out the research attention toward this area then VOSviewer software have been used to analyse the result. Fig. 1 shows the main keywords used by research and their association to each other. Also, it shows that the topic started to have higher attention only after 2013 onward. The result has revealed a promising gap in the field of demand driven supply chain.

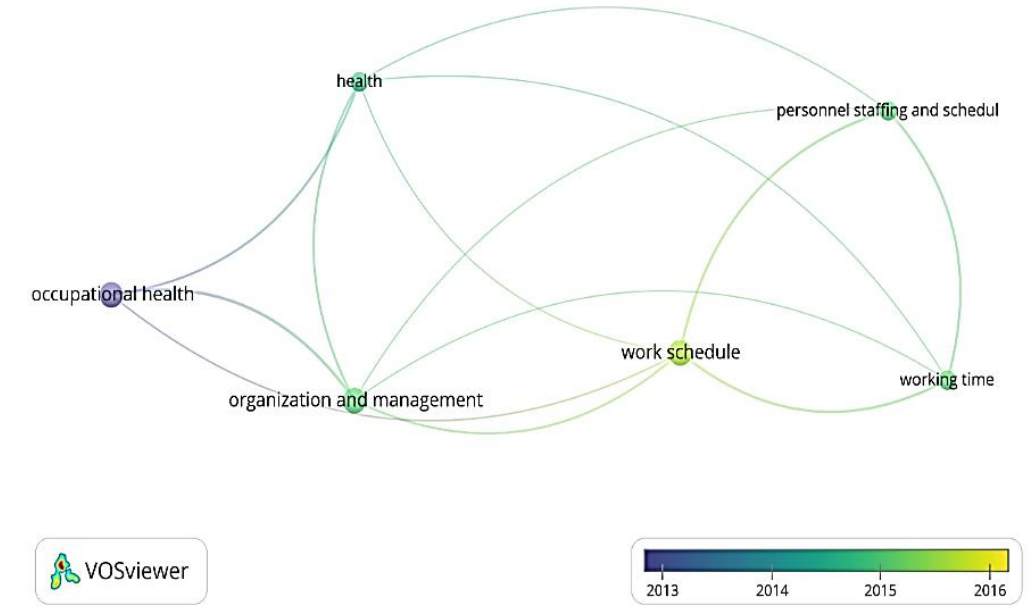

Fig. 1 VOSviewer output for Demand Chain Management, Demand Driven Production, Demand Forecasting, Demand Management, and Demand Optimization keywords 


\section{Demand driven supply chain}

Another search result in only of total 68 publications in multiple filed with 89 only citation so far for all concerned topics of this keyword. Fig. 2 shows the most associated keywords with minimum five occurrences.

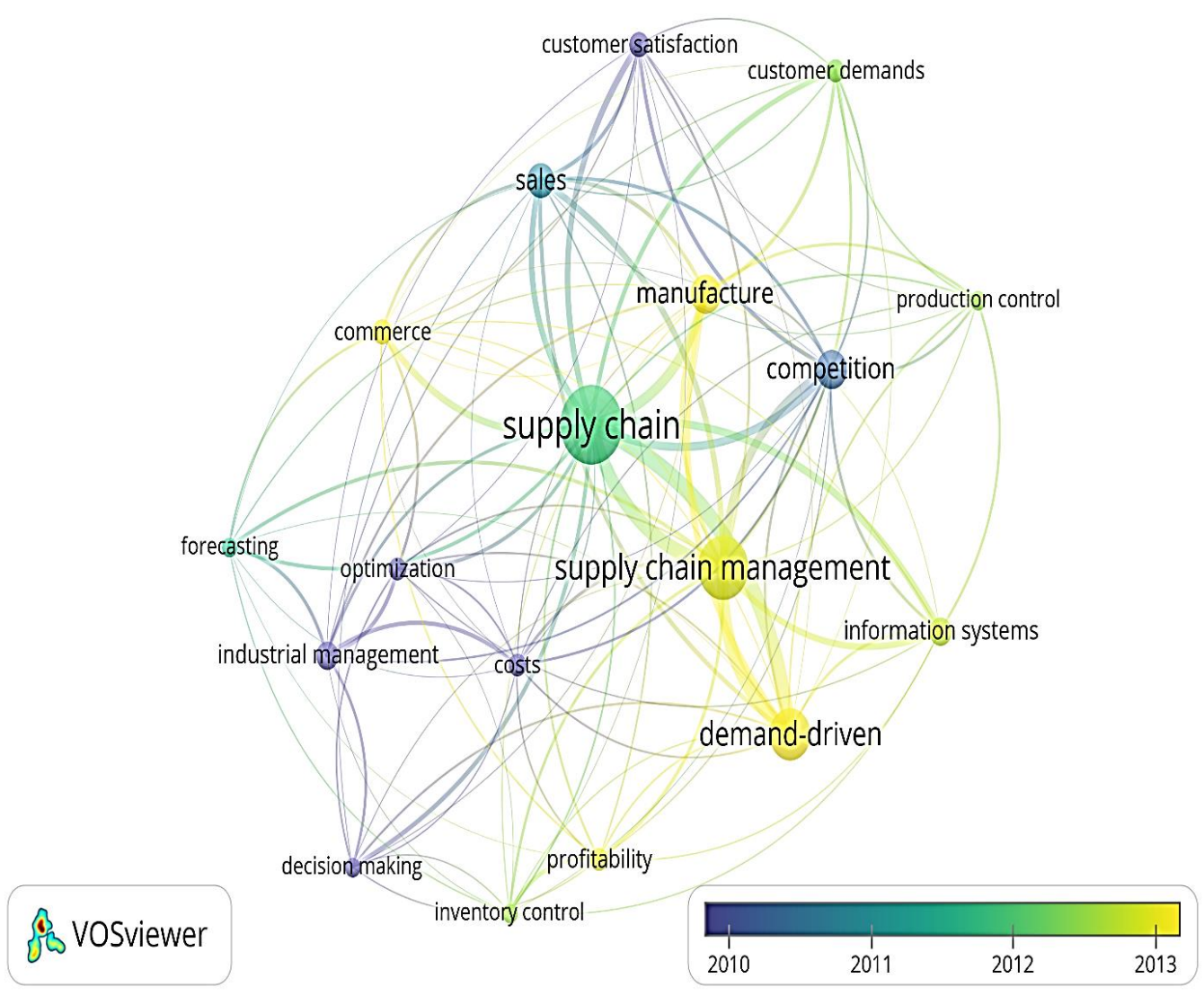

Fig. 2 VOSviewer Demand driven supply chain search result

Likewise, Fig. 3 shows the most commonly used keywords of occurrence more than five times in Scopus search (Demand Driven Supply Chain). The sphere size reflects the relatively occurrence of a specific keyword among others. The connections indicate the associated occurrence with each keyword. The thickness of the connection is the relative number of associated occurrence among other keywords. 


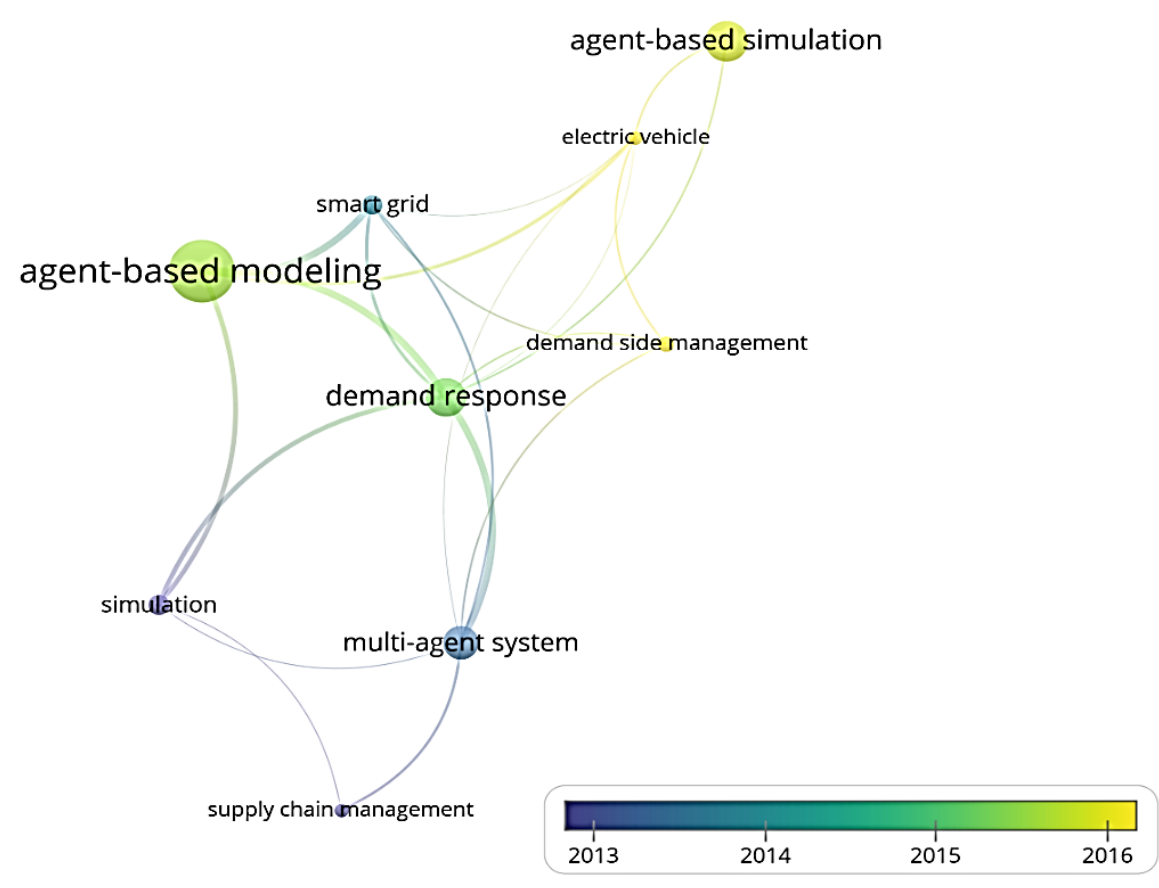

Fig. 3 Analysis of Demand Driven Supply Chain search result with minimum 6 occurrences per keyword

\section{Agent-Based Demand}

Agent based demand is an interactive demand form that uses statistical data to act in a simulated agent with probability behaviour. It mainly used in graphical development software environment like discrete event simulation and virtual reality. A Scopus search have been performed by using Agent Based Demand keyword. The result shows that only 25 publications with 115 citations so far. It is probably related to the technology and knowledge requirements. However, the publication in both areas did not reach up to ten paper per year at most. Fig. 4 shows scholarly output for both target areas of research interest.

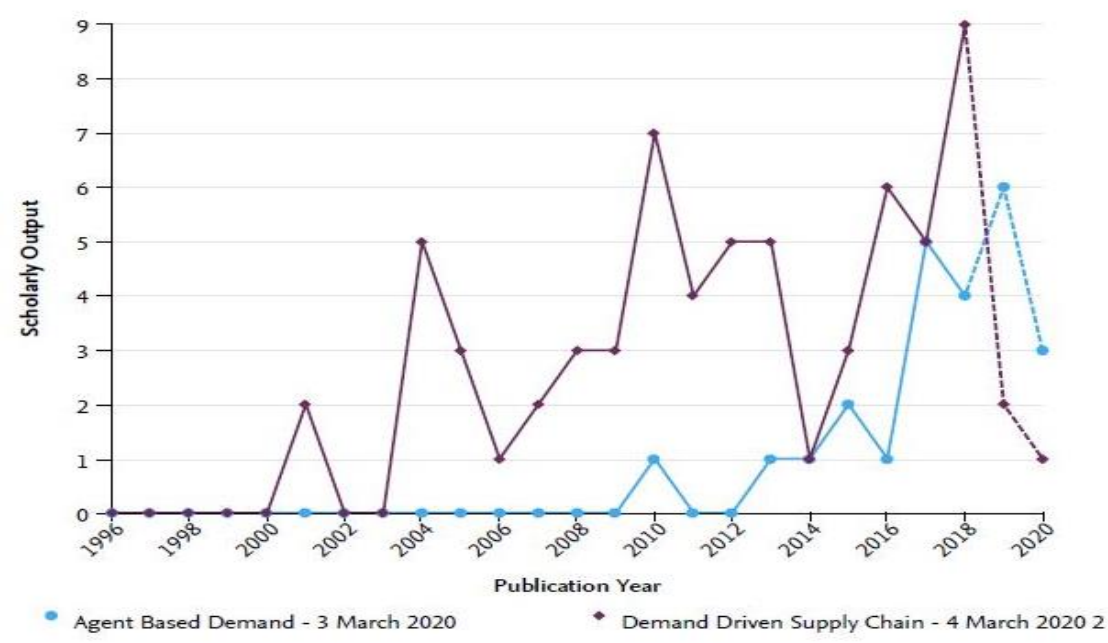

Fig. 4 scholarly output for Agent based demand and demand driven supply chain 


\section{2- Chosen Literature Review}

\section{A. Supply Chain Concept and Boundaries}

Different supply chain management study have been conducted by Mentazer, et al. [1] in order to set up a definition that can be widely agreed on among research. Based on their approach Supply Chain Management can be defined as: All techniques which are used to manage product's flow, goods, materials, or services, along the Supply Chain from upstream through downstream. For the purpose of this definition, upper stream represents the start where raw materials entity, while the downstream may represent the last finish where product is delivered to the end user. The main components involved in the supply chain are product, information flow as well as finance measures. Effectiveness and efficiency can be used as performance measures in order to improve product's quality, lead time, and cost reduction [2]. The main limitation of this definition is that it considered the product from raw material to end used only. However, a new definition is suggesting that the supply chain can be extended to the end of product lifecycle. This extension can help in considering environmental impact by looking into the whole image of material, energy and other supply chain elements into consideration aside from looking only to the side of logistics. So the definition can be: All techniques which are used to manage product's flow, goods, materials, or services, along the row beginning to the end of product lifecycle. Where the beginning is the raw material and the end is used to called the product's grave. This definition is especially important as the evolution of "Digital Shadow" and "Digital Twin" concepts and applications ongoing where information do not get disposed at the end of use but even extend to reuse, remanufacture, recycle and disposal.

\section{B. Supply Chain Management (SCM) Research}

Many SCM research mainly concerns in; procurement, warehousing, production scheduling/planning, and logistics. While all SCM activities are conducted within business organizations and it optimal focuses on reducing expenses, improving quality, reducing lead time and/or increasing product's profitability, within determined constraints. even though such improvements are the main focus of business viewpoint, it can also end up with many advantages to the end customer as a result of competition mostly within mathematical optimization model research area. In this context, many challenges pressure the supply chain management as seeking the optimum performance in order to enhance product's market position and/or profit margin.

Dietrich et al. [3] Study SC optimization through demand shaping maximum profitability mathematical model using cloud-based data model of tightly linked product dependency structure utilizing reliable demand and supply data across the extended supply chain. Hawaidi [4] designed a neural network model to predict variable water demand in order to determine the optimum production in minimum operational cost mathematical model. Mahmud [5] suggest mathematical optimization model of multi vessel batch distillation under fixed demand maximum profit. Venkatadri et al. [6] study the relation between order due date flexibility and manufacturer in synthetic industry production cost reduction mathematical model driven by ordering cost reduction function. 


\section{Supply Chain Computer Simulation}

Supply Chain complexity level and the associated nonconformity led to make computer machine calculation aid as a powerful for decision makers and scientists. some computer programs are used to solve mathematical models and produce data or graphs output in some cases. Due to the nature of complex multivariable nonlinear problem cases, Discrete Event Simulation DES programs are common SC manager's aid that are used to assist in decision making in analytical or scenario based cases. Furthermore, it can be a promising tool with the integration with data technology for the digital shadow/digital twin application by the support of smart city concept and application.

Computer simulation can be used to overview system dynamics, determine mathematical optimum solutions, provide graphical and visual behavioural understanding complex systems, scenario based analysis, and supply/demand forecast [7]. The authors suggest that the integration between Big Data and Simulation can enable multiple data sources to be utilized in evaluating the response of the system to uncertainty as well as in designing scenario based analytical model. However, while Instead, it is agreed that simulation based models are able to mimic the behaviour of the system closely is not an easy task, it is believed that the state of the art in computer simulation is its capability to implement secrete event probability for all entities within the application environment. Additionally, it is argued with the claim that current simulation software is able to produced new results based on existing data as per experimental works. Example software, FlexSim, Arena, and Promode are producing the same results for the programmed models for every run despite a high level of uncertainty.

Ponte et al. [8] developed an agent-based approach by using BMS system to study the impact of demand variation propagation on inventory management by using multiple forecast method scenarios. Based on obtained results they concluded that each scenario can affect the inventory management policy in terms of the bullwhip effect depends on network location. Sahoo and Mani [9] have developed a discrete event simulation model by using ExtendSim. Their objective is to provide a sustainable biomass SC by optimizing the warhorse at bioenergy heat/electricity plant. They use Geographic Information System to predict the potential cost and demand. They suggest to have further developments to include long-term weather data to provide better forecast data. Wisniewski \& Matuszczak [10] studied demand variability as a form of un-certainty within supply chain of fertilizer industry. They focus on understanding the effect of demand fluctuation through the supply chain. Computer simulation is pro-posed to model the supply chain of the fertilizer industry in conditions of uncertainty. The aim of the investigations is twofold: firstly, to understand some of the underlying structures and factors which are generated from demand uncertainty and have impact on fluctuations through the supply chain; they presented the advantages of using simulation and modelling supply chain to solve related issues. Salem \& Haouari [11] investigated a three-echelon stochastic supply chain network design problem in order to minimize the total expected cost. It is agreed that demand and supply combined uncertainties are sources of low performance efficiency. They approach the problem using a simulation-optimization based on an invented method called 'hedging 
strategy' by capturing the randomness of the uncertain parameters. They prove that the invented strategy is viable enough by using a large set of provided data.

Therefore, it can be observed that computer is a powerful machine that can be used to solve supply chain optimization by through liner programming, multilinear programming and non linier programming software. additionally, by combining Fritzson [12] and Beaverstock et al. [13] approaches with the selected literature, it can be concluded that computer simulation offers advantage in the following context:

- Analysing an existing supply chain for better understanding and/or for visually identifying constraints.

- Modelling a supply chain for evaluation purpose (performance measurement).

- Examining a proposed solution or scenario before validating its applicability.

- Tuning SC synchronization to ensure the smooth flow from upstream to downstream.

- It can be used as a tool to strengthen information sharing between SC links especially in the scope of Digital Manufacturing, Digital Shadow or Digital Twin.

- Simulating discrete event complex supply chain cases which is main scope of this research

\section{Demand Uncertainties}

Ideally, an efficient demand fulfillment is an ultimate goal of supply chain. It is usually measured in terms of service level [14]. By backing up the previous statement with Shen \& Liu [15], demand may be defined as: a customer preference toward certain product that motivate $\mathrm{him} /$ her to initiate order to satisfy a preexisting intention. Intuitively, customer expect to satisfy his/her needs as soon as possible to leverage service level. However, the associated uncertainties represent a large source of challenge to the supply chain as it will act as disturbance, where cost is constant optimum value. Demand forecasting is a common practice in which providers using one of common methods to predict future demand [16].

According to Gupta \& Maranas [17], there are two approaches to deal with discrete event, no-linier, demand uncertainties: distribution-based and scenario-based approach, wherever distribution is difficult to obtain. However, Markov-Chain can also work in some situations especially here steady state might be reached in the future. The scenario based tries to deal with the uncertainties as a set of discrete events in order to tackle its behavior. Each scenario has its own probability variables, and hence uncertainty level, which represents the potential occurrence with predefined distribution type or pattern.

Eventually, all mathematical approaches are good to study the certain/foreseeable uncertainties with occurrence challenge in terms of validation accuracy. However, presumptions and assumptions in terms of scenario based approach can be potential promising forecast/optimization technique especially if combined with qualitative measures where simulation can be a powerful tool to examine different variables within the context of discrete event and agent based. 


\section{E. Lean Supply Chain (LSC)}

Lean principals can be applied as an alternative to computational optimization methods to solve supply chain addressed issues in terms of waste "Muda", a contrary measure of efficiency. The main purpose of applying lean approach to reduce waste in all process, logistics operations in the context of supply chain. Waste is defined as any non-added value activities [18]. The waste can be divided into eight types as identified by Pereira [19]: Transportation, Inventory, Motion, Wait, Overproduction, Over processing, Defects, and Skills. It is necessary to coordinate and share information between all corporates or supply chain links to determine these wastes [20].

Ideally, a lean supply chain means smooth material flow from upstream to downstream with minimum/no raw material stock and the same applies to the work in process or finished product buffering, safety stock, which is usually called just-in-time principle [21]. As a result, it requires a high level of certainty as materials need to arrive to each link of the network at the required time to maintain smooth product flow. Based on above literature, it can be concluded that Lean concepts promote a creative way of thinking, brainstorming, applying common sense and idea sharing based on new ideas instead of a common law. Accordingly, lean methodology can be classified as a scenario based supply chain optimization due to Root Cause Analysis and kaizen where "what if" is one of common solution proposal way. Subsequently, solution application starts in a limited scope until proves its validity. Table 1 compares between mathematical supply chain optimization and lean supply chain improvement methods.

Table 1 Mathematical Vs Lean supply chain optimization

\begin{tabular}{|c|c|c|}
\hline & $\begin{array}{l}\text { Mathematical } \\
\text { Optimization }\end{array}$ & $\begin{array}{l}\text { Lean } \\
\text { Methodology }\end{array}$ \\
\hline Strategy & $\begin{array}{l}\text { Best income with minimum } \\
\text { investment }\end{array}$ & Eliminating waste \\
\hline Focus & Profit / resource optimization & $\begin{array}{l}\text { Smooth flow/ stock } \\
\text { reduction }\end{array}$ \\
\hline Inventory policy & Forecast based & Demand driven \\
\hline Efficiency & $\begin{array}{l}\text { Higher emphasis on market share } \\
\text { and customer service (agile) }\end{array}$ & $\begin{array}{l}\text { High emphasis on } \\
\text { efficiency }\end{array}$ \\
\hline Bull WIP effect & Higher due to buffering stock & $\begin{array}{l}\text { Low due to stock } \\
\text { limitations }\end{array}$ \\
\hline $\begin{array}{l}\text { Service cycle } \\
\text { strategy }\end{array}$ & $\begin{array}{l}\text { Safety stock is maintained to face } \\
\text { demand and lead time uncertainty }\end{array}$ & $\begin{array}{l}\text { High flexibility and } \\
\text { faster reaction to } \\
\text { market changes }\end{array}$ \\
\hline
\end{tabular}

\section{F. Demand Uncertainties}

Demand represents the downstream where the supply chain ends with. It agreed with Yunus, et al. [22] that customer is the motivation of any business since he/she is the end user of the product. To this extent, customer is more complex than only represented as a variable in a mathematical equation! It is strongly believed that customer behaviour is a sophisticated group of vectors which is eventually reflected in a form demand behaviour as a result. It is very important to cover as more aspects of demand as possible in order to analyse supply chain, 
study scope, and to obtain an adjacent to reality form. Ideal service level, $99.99 \%$ customer satisfaction, might not be achievable in real world which means that some demand is certainly not satisfied, though it is not recorded. Mad customers can affect the business more than marginal profit loss. He can promote negative impression, finds alternative product or simply switches to another supplier if applicable. This behaviour can lead to a reduction in the market share [23].

Moreover, demand is a complex formulation of internal and external factors. Internal factors are those considered in supply chain control equations like quality, service level, lead time and stock availability ...etc. The external factors include the shape, pattern, season, and competition of demand forces. As a result of wide range of research is usually focusing on limited aspect or case of demand. Uncertainty is normally associated to every links of supply chain to an extent. The higher level uncertainty is; the more resources are needed to cope with. The practice of using demand forecasting methods or simply using average values may provide a solution in certain cases, but all methods are history based and they might be good in liner cases especially stable demand. However, market era is shifting toward mass customization and market condition rapid changing as a result to the communication revolution. At the same time, the supply is becoming hard to predict with high uncertainty which make simulation as an essential tool to cope with rapidly changing market. Fig. 5 illustrates an example of lead time and demand with distribution uncertainties.

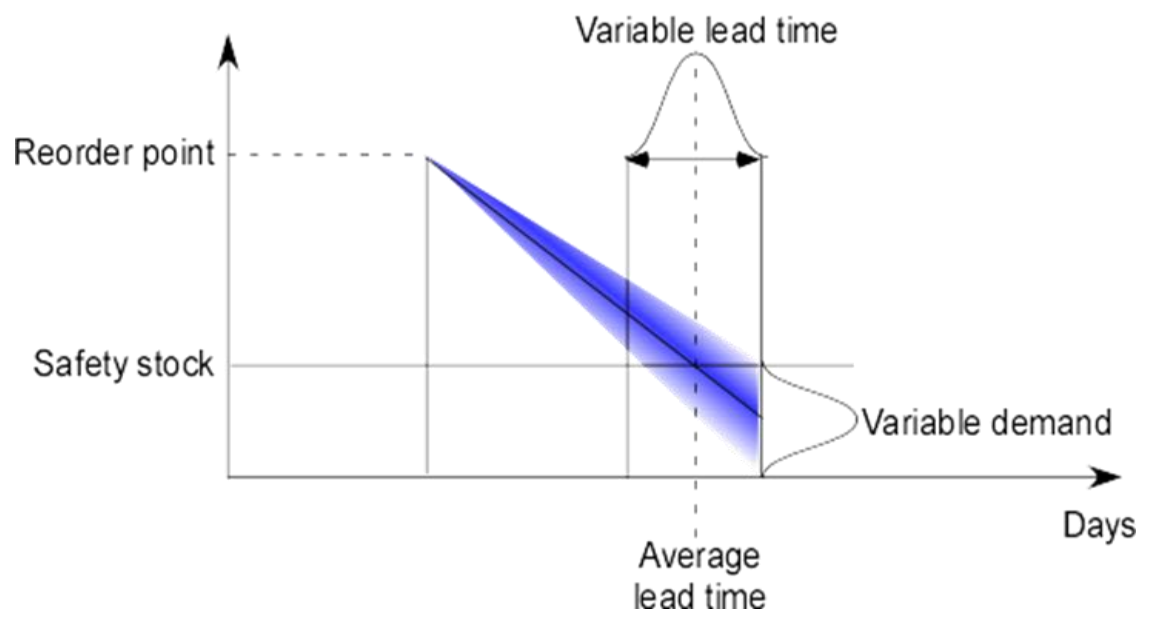

Fig. 5 Lead time and demand deviations representation [28]

However, it can be related to customer needs, competition, alternative products, and/or product availability expectations, to wait or not to wait in case of product is not instantly available. In some businesses queuing is common practice in order to reduce the overhead. Such businesses include: airport check in/out, restaurants, supermarkets, call centres, public services etc. According to Torio \& Dayal, [24], customers can fall into three categories in terms of waiting: delighted, satisfied, and dissatisfied. Fig. 6 shows an example of customer satisfaction feedback based on the waiting time. 


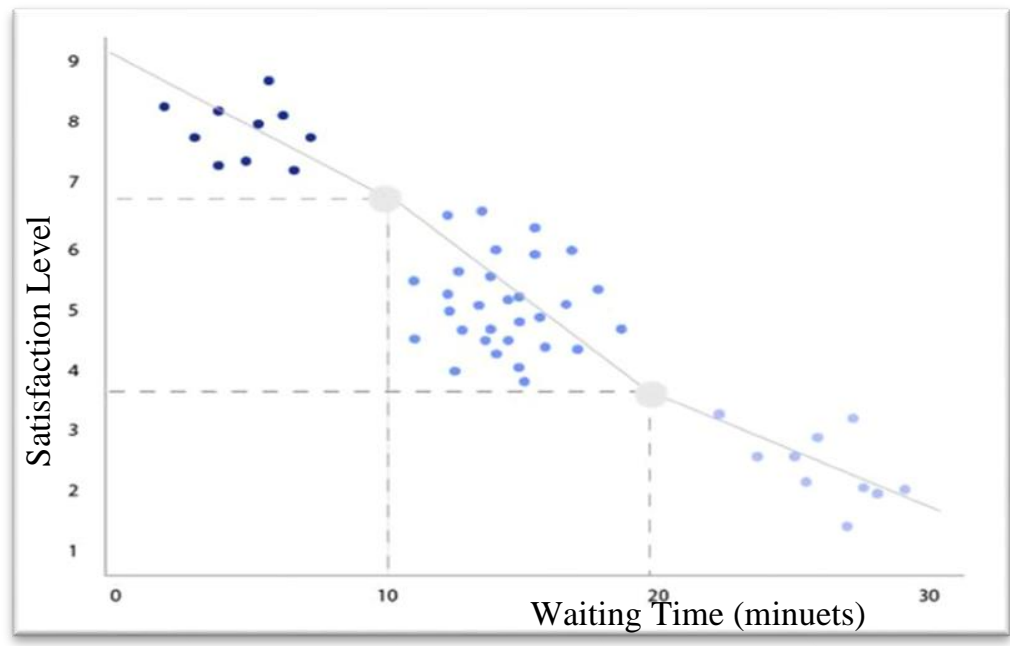

Fig. 6 Customer satisfaction and waiting time relation in [24]

In certain instances, an exceptional demand behaviour might occurs on certain products. Such behaviour is called rationing and shortage gaming. It happens when demand exceeds supply in a short time due to some unexpected associated event which will lead to a panic demand or non-real demand in other words. In many cases of supply shortage, customers tend to exaggerate their actual needs. After the supply shortage recovered, the demand will disappear suddenly and cancellations substitute demand. The effect of this behaviour or wrong anticipation is that it will counterfeit the actual demand along the supply chain [25].

\section{G. Summary and Conclusions}

Supply chain management (SCM) is an essential business practice in terms of profitability, inventory management, customer service (lead time/agility), and demand forecast/management. It can be observed that SCM is not directly concerned in technical aspects of production, warehousing methods or transportation techniques. alternatively, lean principals can be applied to supply chain in order to eliminate what defined as waste. The main three waste, Muda, Mura and Muri, can be reduced by using creative problem solving techniques through suggestion and scenario application or systematic technique like value streaming. It is agreed with Colwell [26] converting supply chain from push to just in time methodology can increase agility and leanness at the same time but at it can lead to a huge risk if any unforeseen event occurred and hence high uncertainty. In addition, reducing stock size, manpower, and machinery might have a management return on investment capital, but when reduction reaches to a point that limits the supply chain flexibility in respond or adapt to unexpected event, disruption in supply or sudden demand change, like what happened in COVID19 pandemic where protective equipment's and ventilator demand surges out of global response capacity. The relation of lean and agile supply chain is shown in Fig. 7. 


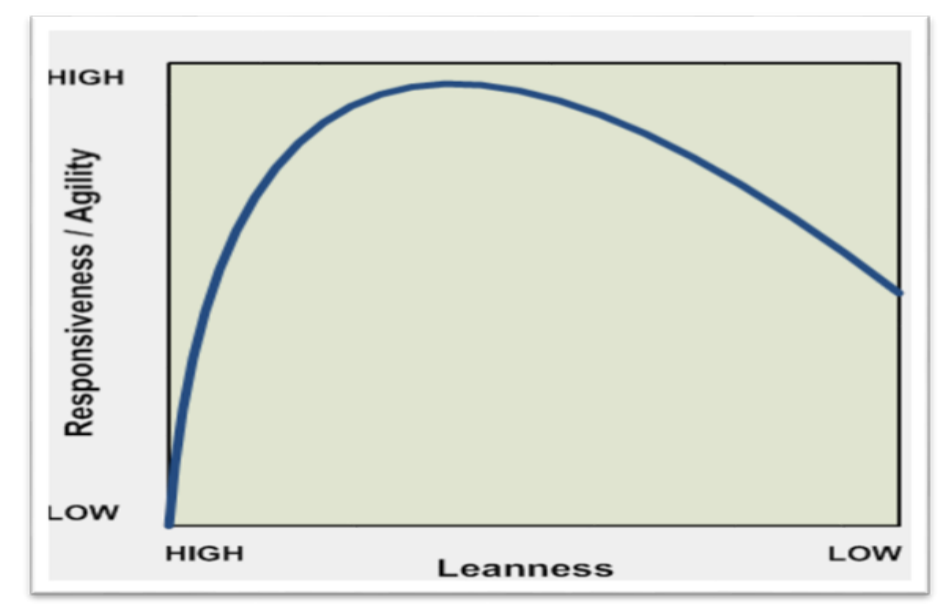

Fig. 7 The relation between leanness and agility in [26]

Hence, profitability based approaches, including cost reduction, are proven effective methods to be used for improving agility while better increasing business outcome. At the same time, only profitability not necessarily assure the efficiency of the supply chain where optimization equation may consider certain decision variables, while neglect other variables. On the other hand, as cited above, using lean principles to improve supply chain can have agility advantage as well, but such improvement can be time consuming process.

However, lean approach might compromise agility if associated with high supply/demand uncertainties which considered as a drawback although it might be proven as an efficient solution method by big companies like Toyota [27]. Additionally, demand can be unexpected due to unexpected event like in case of epidemic or crises. Such behaviour should have considered in order to have supply chain system readiness and extend it to more resilience to retrieve its regional performance state to some extent.

\section{3- Methodology}

In this section the complex uncertainty problem will be discussed focusing on demand as a main motivation of the research where a gap has been found and a simulation model is developed to tackle the problem. As far as this research is conducted, researches measure customer satisfaction in terms of service level only, hit or miss; waiting time is not considered.

Thus, this study has been developed to include waiting time as a measure and status of customer satisfaction in addition to the maximum waiting limit which can be determined according to business, then a purchase may be initiated or simply just leave without purchasing due to the long waiting time.

\section{A. Conceptual Design}

A block conceptual design has been developed according to the literature review Section 2. The block is used to tackle a product rather than just a software. In order to simplify the experiment, two inputs have been used to simulate the waiting time distribution and the customer happiness status of waiting time length. Although the demand is agent based, the initiation event has been made through the source control of the simulation software. It is 
related to the fact that demand itself is not initially existed within the software which is the case of Object Oriented software environments as in FlexSim software program. However, the developed conceptual block design is flexible to add, modify or remove features according to desired functional requirements. Fig. 8 shows the conceptual block design of the chosen demand agent for the experiment purpose.

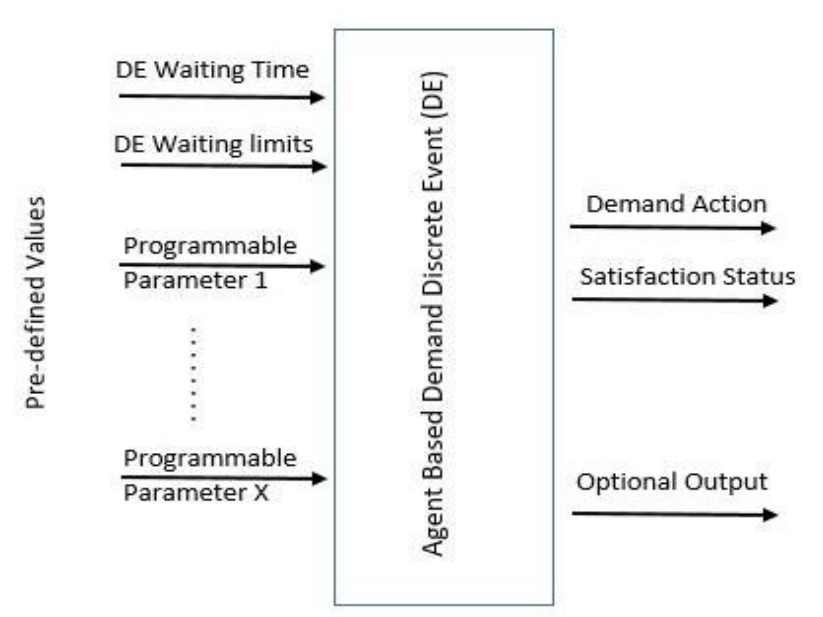

Fig. 8 Conceptual block model design for demand agent

\section{B. Behavioural Design}

The purpose of the proposed demand agent is to mimic certain aspect of demand where waiting time and product availability is a matter. So it is mainly a behavioral based object where it can be located at the end of the supply chain.

\section{Demand Agent Feature}

- Based on common demand forecast methods, a product will be available according to certain distribution. Where a product arrives before customer request it, customer just picked it with $100 \%$ satisfaction rate. In case of demand driven supply chain, where product can only have made after demand, the demand object still valid with adjusted satisfaction indicator.

- Demand agent, hence customer, decisions are affected by product availability. In case of queue system like public service, fast food, public transportations, ... etc. customer needs to wait before he/she receive his/her order. It has been identified that there is limited empirical studies within this field of. Hence, any implementation should be able to facilitate waiting state capability.

- Optional status and action signals visualization to serve as non-statistical evaluation aid.

\section{Action Table}

Action table contains the desired main customized demand object action from the creation to the end of the scope of the research where demand end up either with satisfaction 
or non-satisfaction. Table 2 summarise the desired actions according to the design requirements.

Table 2 Demand agent action table

\begin{tabular}{ll}
\hline Action & \multicolumn{1}{c}{ Reaction } \\
\hline On creation & $\begin{array}{l}\text { Wait in the queue. It can be configured to notify } \\
\text { the production line to execute an order request in } \\
\text { case of demand based production strategy } \\
\text { adopted. }\end{array}$ \\
\hline On product available & $\begin{array}{l}\text { Perform hit action (get the product). Pick it then } \\
\text { drop it in the destination place in order to perform } \\
\text { additional operations if necessary }\end{array}$ \\
On product unavailable & $\begin{array}{l}\text { Mainly to wait until further action configured. If } \\
\text { the waiting time reaches the maximum defined } \\
\text { time, then perform miss action (leave the location } \\
\text { to act like change of mind). }\end{array}$ \\
\hline
\end{tabular}

\section{Simulation Model Result}

Satisfaction have been defined as an opposite percentage of waiting. Where zero, or no, waiting is $100 \%$ satisfaction or very happy, up to $75 \%$ is acceptable or Happy, more between $75 \%$ and 35 is not happy, below 35 is sad and angry is $0 \%$ of satisfaction or a $100 \%$ of waiting time reached, no purchase occurs and customer leaves. After visually validating the model during the trial runs, four different discrete event distributions have been tested with a simulation. Both product supply side and demand side have been configured at the same distribution values. The delay and disturbance of customer to reach the product supply is omitted as it uses the same rules throughout the entire experiment. Table 3 shows different configuration have been used in the simulation experiment. Waiting time is set to uniform distribution minimum 5 and maximum 7 relatively

Table 3 Distribution types and values for the experiment model

\begin{tabular}{|c|c|c|}
\hline Distribution \# & Distribution Type & $\begin{array}{c}\text { Distribution } \\
\text { Values }\end{array}$ \\
\hline \multirow{2}{*}{$\mathbf{1}$} & Uniform & $\begin{array}{c}\text { Min }=5 \\
\text { Max }=15\end{array}$ \\
\hline \multirow{2}{*}{$\mathbf{2}$} & Normal & $\begin{array}{c}\text { Mean }=10 \\
\text { deviation }=5\end{array}$ \\
\hline \multirow{2}{*}{$\mathbf{3}$} & Triangular & Mode $=10$ \\
& & Min $=5$ \\
& Exponential & Max $=15$ \\
\hline \multirow{2}{*}{$\mathbf{4}$} & & Scale $=10$ \\
& & Position=0 \\
\hline
\end{tabular}

Four run times have been carried out for every configuration in Table 7, the running time is up to the first 1000 product unit creation each. The results are exhibited in Table 4. 
Table 4 Simulation experiment results

\begin{tabular}{|c|c|c|c|c|c|c|}
\hline 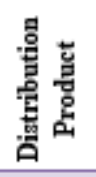 & 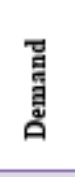 & 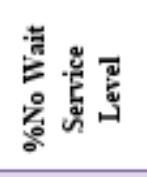 & 氙 & 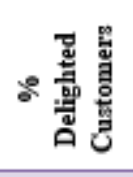 & 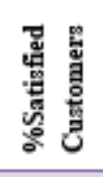 & 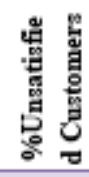 \\
\hline 1 & 1 & 77.11 & 93.75 & 93.8 & 3.1 & 3.1 \\
\hline 1 & 2 & 89.13 & 98 & 95 & 2 & 3 \\
\hline 1 & 3 & 58.1 & 91.75 & 90.7 & 6.2 & 3.1 \\
\hline 1 & 4 & 83 & 97.05 & 92.2 & 4.9 & 2.9 \\
\hline 2 & 1 & 90 & 96.51 & 94.2 & 3.5 & 2.2 \\
\hline 2 & 2 & 53.24 & 84.69 & 86.7 & 7.1 & 6.1 \\
\hline 2 & 3 & 57.89 & 89.79 & 84.7 & 10.2 & 5.1 \\
\hline 2 & 4 & 72.94 & 90 & 88.9 & 6.1 & 5.1 \\
\hline 3 & 1 & 85.39 & 95.91 & 94.9 & 4.1 & 1 \\
\hline 3 & 2 & 96.84 & 100 & 98 & 2 & 0 \\
\hline 3 & 3 & 75 & 98.75 & 94.9 & 5.1 & 0 \\
\hline 3 & 4 & 70 & 94.84 & 91.8 & 7.2 & 0 \\
\hline 4 & 1 & 94.5 & 95.65 & 100 & 0 & 0 \\
\hline 4 & 2 & 69.79 & 79.80 & 94.2 & 3.8 & 1.9 \\
\hline 4 & 3 & 91.2 & 95.78 & 95.8 & 4.2 & 0 \\
\hline 4 & 4 & 90.47 & 94.25 & 96.6 & 3.4 & 0 \\
\hline
\end{tabular}

\section{Summary and Finding}

It can be observed that three dimensional graphical simulation software can provide additional visual advantage for extra examination at supply chain level. In addition, there are many ways to perform supply chain simulation where agent based demand can successfully serve the purpose of demand agent design where natural variables like walking, transportation, loading movement are inherited from the best representing object, e $\mathrm{g}$ a human can represent a human.

Waiting is an important variable in demand. It can affect the service level directly as proven by the experiment above. So, it is highly recommended to integrate it in supply chain simulation in order to have better understanding of the whole behaviour image and to find better ways to optimise its performance through discrete event or lean methodology. 


\section{4- Conclusions}

Simulation is a powerful tool which is widely used by SC managers to assist in decision making mainly toward optimized performance. It can be used to overcome the complexity of the supply chain and to exanimate a proposed or expected scenarios before applying the in the real application.

A better understanding of demand nature leads to better customer service and supply chain performance as a result. Three dimensional graphical simulation software is an attractive choice to be used in addition to the calculation aid because these programs can calculate input variable and provide the result in addition to the runtime visual status exposure. It is recommended to apply the obtained solution by using FlexSim software as a white box examination technique in order to validate it before implementing in the real situation. Also, it is noted that customers' waiting time does not take a lot of attention in research. While needs are the main driver for demand, alternatives can serve as a relief where demand is not easy to satisfy. Waiting time can be a part of utility which can represent one of customer satisfaction measures, otherwise usually obtained by feedback forms. However, unsatisfied customers can affect business in the long term by reducing its market share in favour of alternative or competitors.

Agent based demand have been successfully developed. It behaves the same as in the desired design requirements. It is based on a modified task executer flow item that is supplied originally by FlexSim library. This object can provide extra option to in terms of supply chain in order to integrate demand, particularly demand driven systems.

Deviation is a source of challenge in any supply chain. It has been observed that even if the supply and the demand have the same distribution variables, the service level can be as little as 53\%, worst case. Considering wait of about five to seven time uniform distribution can enhance the service level performance by minimum between $04 \%$ - 33\% at statistical distribution in Table 4. It is noted that the uniform and normal distribution are having more deviation compared with triangular and exponential distribution. The proposed agent can be used as a base to develop more sophisticated demand which can be used in digital shadow technology and other integrated smart systems.

\section{References}

[1] J. T. Mentazer, W. DeWitt and J. S. Keebler, "Defining Supply Chain Management," Journal of Business Logistics, vol. 22, no. 2, 2001.

[2] F. Persson and J. Olhager, "Performance simulation of supply chain designs," International Journal of Production Economics, vol. 3, no. 77, pp. 231-245, 2002.

[3] B. Dietrich, M. Ettl, R. D. Lederman and M. Petrik, "Optimizing the End-to-End Value Chain through Demand Shaping and Advanced Customer Analytics," In: Karami I.A. \& Srinivasan ed. Proceedings of the 11th International Symposium on Process Systems Engineering, 15-19 July 2012, Singapore, 2012.

[4] E. Hawaidi, "Simulation Optimization and Flexible Scheduling of MSF Desalination Process Under Fouling," Bradford University, 2011.

[5] M. Mahmud, "Optimal Design and Operation of Multivessel Batch Distillation with Fixed Product Demand," Bradford University , 2010.

[6] U. Venkatadri, A. Srinivasan, B. Montreuil and A. Saraswat, "Optimization Based Decision Support for Order Promising in Supply Chain Networks," International Journal of Production Economics, vol. 103, p. 117-130, 2006. 
[7] A. A. C. Vieira, L. M. S. Dias, M. Y. Santos, G. A. B. Pereira and J. A. Oliveira, "Supply chain hybrid simulation: From Big Data to distributions and approaches comparison," in Simulation Modelling Practice and Theory, Gualtar, Braga, Portugal, 2019.

[8] B. Ponte, E. Sierra, d. 1. F. David and J. Lozano, "Exploring the interaction of inventory policies across the supply chain: An agent-based approach," Computers \& Operations Research, vol. 78, pp. 335-348, 2017.

[9] K. Sahoo and S. Mani, "GIS based discrete event modeling and simulation of biomass supply chain," in 2015 Winter Simulation Conference (WSC), Huntington Beach, CA, 2015.

[10] T. Wisniewski and A. Matuszczak, "Simulation-based analysis of demand variability in supply chain," World Review of Intermodal Transportation Research, vol. 6, no. 4, pp. 319-335, 2017.

[11] R. Salem and M. Haouari, "A simulation-optimisation approach for supply chain network design under supply and demand uncertainties," International Journal of Production Research, vol. 55, no. 7, pp. 1845-1861, 2017.

[12] P. Fritzson, Principles of Object Oriented Modeling and Simulation with Modelica 2.1, Wiley-IEEE Press, 2004.

[13] M. Beaverstock, A. Greenwood, E. Lavery and W. Nordgren, Applied Simmulation Modeling and Analysis using FlexSim, 2nd ed., S. Warr and K. Bobo, Eds., Orem, UT: FlexSim Software Products Inc., 2012.

[14] F. R. Jacobs and R. B. Chase, Operations and Supply Chain Management, 13 ed., McGraw-Hill/Irwin, 2010.

[15] Q. Shen and H. Liu, "Demand Uncertainty, Dynamic Learning and Exit in Competitive Markets," : Marketing Department, The Wharton School, University of Pennsylvania, 2012. [Online]. Available: https://marketing.wharton.upenn.edu. [Accessed 17 August 2013].

[16] J. S. Armstrong and K. C. Green, "Demand Forecasting: Evidence-based Methods," : Department of Econometrics, Monash University, working paper 24/05 ISSN 1440-771X., 2005. [Online]. Available: http://www.buseco.monash.edu.au. [Accessed 10 August 2013].

[17] A. Gupta and C. D. Maranas, "Managing demand uncertainty in supply chain planning," Computers and Chemical Engineering, vol. 27, pp. 1219-1227, 2003.

[18] J. Cottynab, H. Van Landeghemb, K. Stockmana and S. Derammelaere, "A method to align a manufacturing execution system with Lean objectives," International Journal of Production Research, vol. 49, no. 14, pp. 4397-4413, 2011.

[19] R. Pereira, "The Seven Wastes," iSixSigma, vol. 5, no. 5.[online] Available at <http://lssacademy.com> [Accessed 10 May 2013], 2009.

[20] D. Nightingale, "Integrating The Lean Enterprise," Lean Supply Chain Management Principles and Practices, vol. [lecture] : Massachusetts Institute of Technology 3rd October. Available at:<ocw.mit.edu> [Accessed 23 July 2013], 2005.

[21] N. Wright, "Lean and Agile Supply Chain," Scandinavian Brewers' Review, vol. 67, no. 4, pp. 16-21, 2010.

[22] M. Yunus, B. Moingeon and L.-O. Laurence, "Building Social Business Models: Lessons from The Grameen Experience," Long Range Planning, vol. 43, pp. 308-325, 2010.

[23] M. A. Waller, B. D. Williams, A. Heintz Tangari and S. Burton, "Marketing at the retail shelf: an examination of moderating effects of logistics on SKU market share," Journal of the Academy of Marketing Science, vol. 38, pp. 105-117, 2010.

[24] J. Torio and R. Dayal, "Break Point Analysis: Gaining Insight into Customer Satisfaction and Reducing over Investment," 18 June 2013. [Online]. Available: http://www.uxmag.com. [Accessed 15 July 20013].

[25] H. L. Lee, V. Padmanabhan and S. Whang, "The Bullwihp Effect in Supply Chain," Sloan Management Review, vol. 38, no. 3, pp. 93-102, 1997.

[26] T. Colwell, "Lean vs Agile Supply Chain... or Can We Have Both?," 21st Mar. Acuity Consultants Ltd., n.d. [Online]. Available: http://acuityconsultants.com. [Accessed 29 June 2013].

[27] J. K. Liker, The Toyota Way, New York, NY: McGraw-Hill, 2004.

[28] M. Baudin, "Safety Stocks: Beware of Formulas," 16 Feb., 2012. [Online]. Available: http://michelbaudin.com. [Accessed 30 August 2013]. 